\title{
Congenital Heart Disease: Global Burden and Challenges to Eliminate Health Disparities
}

\author{
Irina Alina $\mathrm{CuCu}^{1,2}$ and Mariana Carmen Chifiriuc ${ }^{1,2^{*}}$ \\ ${ }^{1}$ Microbiology Immunology Department, Faculty of Biology, University of Bucharest, Romania \\ ${ }^{2}$ The Research Institute of the University of Bucharest, Romania
}

\begin{abstract}
Congenital heart disease ranks first among mortality causes by birth defects in children under 5-years-old. In 2016, The World Health Organization informed that 9,274,915 children died due to heart anomalies. Congenital heart defects can have genetic causes, but can also result after exposure to several risk factors (i.e. environmental factors, maternal health and age). Prevention and screening are key measures for lowering mortality rate among infants with heart defects. Appropriate surveillance is required in order to identify and support interventions. However, this is a difficult task, because public health workforce, epidemiologists and pediatric heart surgeons are understaffed. This paper aims to provide information about congenital heart disease incidence worldwide, risk factors and discuss health disparities in developing countries.
\end{abstract}

Keywords

Birth defects, Congenital heart disease, Health disparities, Economical burden, Epidemiology, Prevention

Abbreviations

CHD: Congenital Heart Disease; WHO: The World Health Organization; CO: Carbon Monoxide; USA: The United States of America; CDC: The Center for Disease Control and Prevention

\section{Introduction}

Birth defects or congenital malformations are described as anomalies that can be detected prenatally, at birth or later in life. Although $50 \%$ of these congenital defects have no apparent cause, some factors were found to influence child development. Worldwide, it is estimated that every year a number of 8 million children, representing almost $6 \%$ of total births globally, are born with different types of congenital anomalies. This estimated number is associated with birth defects related to a genetic origin (almost 25\%); an additional number of children, which remains partially unknown, are born with some kind of birth defect related to other factors. These risk factors, cause almost $10 \%$ of birth defects and can be of various nature: environmental issues, infections, alcohol consumption, nutrition, smoking, maternal age and weight, parental consanguinity and multi-fetal pregnancies [1-6]. According to the World Health Organization (WHO), $23,951,042$ million children under the age of 5 years old died in 2016 due to birth defects. Table 1 provides information about the cause of death attributable to a type of birth defect.

This paper aims to bring front and center the subject concerning congenital heart disease, its major risk factors and the health disparities observed in regard to this pathology.

\section{Congenital Heart Disease: Mortality Rate on the Rise or at an All Time Low?}

Being ranked first among causes of death due to birth defects in children under 5 years old, congenital heart disease (CHD) represents a major health issue and impacts both the lives of children and their families. CHD ranges from simple to complex, the spectrum of defects being divided into: i) Simple (i.e. atrial septal defect, ventricular septal defect), ii) Moderately complex (i.e. atrioventricular septal defect, congenitally corrected transposition of the great arteries, Fallot tetralogy) and iii) Complex (i.e. tricuspid atresia, double inlet left ventricle, heterotaxy syndrome). CHD's incidence

*Corresponding author: Mariana Carmen Chifiriuc, Microbiology Immunology Department, Faculty of Biology, The Research Institute of the University of Bucharest, Spl. Independentei 91-95, Sector 5, Bucharest, Romania, Tel: +40766728315, Fax: 0213151877, ORCID iD: 0000-0001-6098-1857

Accepted: November 24, 2018

Published online: November 26, 2018

Citation: Cucu IA, Chifiriuc MC (2018) Congenital Heart Disease: Global Burden and Challenges to Eliminate Health Disparities. Ann Public Health Reports 2(1):26-29 
Citation: Cucu IA, Chifiriuc MC (2018) Congenital Heart Disease: Global Burden and Challenges to Eliminate Health Disparities. Ann Public Health Reports 2(1):26-29

Table 1: Mortality rate due to types of birth defects on a global scale in 2016 (based on data reported by WHO).

\begin{tabular}{|l|l|l|}
\hline Birth defects & Total number of deaths on a global scale & \% of total number of deaths by birth defect \\
\hline Neural tube defects & $2,557,839$ & $10.68 \%$ \\
\hline Cleft lip and cleft palate & 129,535 & $0.54 \%$ \\
\hline Down syndrome & 422,047 & $1.76 \%$ \\
\hline Congenital heart anomalies & $9,274,915$ & $38.72 \%$ \\
\hline Other chromosomal anomalies & 860,730 & $3.6 \%$ \\
\hline Other congenital anomalies & $10,705,976$ & $44.7 \%$ \\
\hline
\end{tabular}

\begin{tabular}{|c|c|}
\hline 2016 & $\begin{array}{l}\text { - } 9,274,915 \\
\cdot 38.72 \% \text { of total deaths caused by birth defects }\end{array}$ \\
\hline & $\begin{array}{l}\text { - 9,561,366 } \\
\cdot 39.1 \% \text { of total deaths caused by birth defects }\end{array}$ \\
\hline & $\begin{array}{l}\cdot 10,355,316 \\
\cdot 41 \% \text { of total deaths caused by birth defects }\end{array}$ \\
\hline 2000 & $\begin{array}{l}\cdot 11,796,517 \\
\text { - } 42 \% \text { of total deaths caused by birth defects }\end{array}$ \\
\hline
\end{tabular}

Figure 1: Global trends of mortality rate due to CHD over the years (based on data reported by WHO).

is hard to determine, being estimated between 6 and 13 per 1,000 live births. The most precise estimation that is taken into consideration nowadays has established that this illness occurs in 8 per 1,000 live births $[6,7]$. With the help of prenatal screening, genetic testing, and the advancement of healthcare, this estimation became more precise than in its previous years, but it still has an ambiguous incidence. All this time it wasn't about how low the mortality rate was and how it became higher with time, but it was rather about the advancement of technology that helped us realize the magnitude of this illness. While all continents are affected by this type of birth defect, there is a hierarchy among them: Asia occupying first place, while Europe comes in second place [8]. Some studies tried to find a connection between the baby's gender and whether this can be a determinant of CHD [9-13]. While some said that boys are more prone to this pathology, in other studies resulted that female sex has a higher incidence than male gender. However, ultimately, there is no certainty that this disease is affecting one gender more than the other. More up to date studies should be published regarding this issue and an appropriate meta-analysis should be conducted in order to establish if gender can be taken into consideration in the future when screening for possible birth defects. In spite of the fact that we do not know if gender plays a role as a congenital heart disease determinant, there are specified risk factors associated with this pathology. The etiology of CHD is multi-factorial and it has to be taken into consideration both environmental and genetic causes. When it comes to environmental factors, some pollutants, such as $\mathrm{PM}_{10}$ and carbon monoxide ( $\mathrm{CO}$ ), should be avoided because they are related to cardiac anomalies. Also, mothers over the age of 35 , or with a family history of CHD, those who do not have diabetes but present higher plasma glucose values measured during early pregnancy, or those who smoke, consume alcohol, amphetamines and salicylate during pregnancy, present a higher risk of giving birth to an offspring that suffers from a heart condition [3,14-17].

In present times, with the advancement of surgical procedures and timely diagnosis the mortality rate has decreased over time at a global level. Based on data retrieved from WHO Figure 1 shows how the mortality rate went lower over the years. Although a slight decrease of this rate can be noticed, the prevalence of adults with congenital heart disease still remains high, and more medical staff should be trained in order to attend their health related needs. Women with congenital heart disease who decide to go through pregnancy should be counseled by a multidisciplinary team before making this decision, in order to assess the risk imposed by pregnancy on them and their unborn child $[18,19]$.

\section{The Impact of CHD Screening}

Several states of The United States of America (USA) have implemented policies regarding newborn screening for congenital heart disease in 2013. The results were impressive, showing a $33 \%$ decline in infant death due to critical CHD. It sent such a powerful message that 8 states managed to acquire this death rate decline in such a short period of time, that almost all states across the USA are now introducing 'pulse oximetry' screening as mandatory to help detect critical CHDs. The Center for Disease Control and Prevention (CDC) presented that the cost for this type of screening can come to about $5 \$$ or $14 \$$ for each newborn. In case the test fails other tests that are more expensive and time consuming are needed in order to diagnose the infant. CHD diagnosis and treatment needs specialized physicians, that are insufficient around the world. Low-income countries tend to have a higher fertility rate, a palpable absence of medical human resources and a shortage of screening tests, due to their 
financial constraint and consequently, they are more affected both by birth defects and cardiac anomalies [20].

\section{Health Disparities - A Real Setback When it Comes to CHD Prevention and Care}

Pediatric cardiovascular surgeons are one of the main resources when it comes to CHD care. Worldwide, one third of babies born with CHD, are in need of some kind of cardiac intervention, turning to open-heart surgery most of the time. While programs where experienced surgeons are volunteering to go to middle and low-income countries are ascending, more quality pediatric heart surgeons should be trained in order to minimize the burden that CHD inflicts on developing countries. But are pediatric cardiovascular surgeons the only ones that are understaffed? The answer is simple: No. To be able to handle interventions for such a complex pathology like CHD, the surgeon should work together with a skilled team formed of pediatric cardiologists, anesthesiologists, intensivists, nurses and perfusion technologists [21,22].

In our opinion, the lack of epidemiologists and public health personnel in various parts of the world represents an enormous issue that also affects CHD prevention and care. In order to know which part of the world lacks healthcare interventions, the priority should be to initiate projects to gather more reliable scientific data that specialists can be sure of. Some countries have not provided data in such a long time that estimating the real mortality rate or the incidence of CHD at birth is not made possible. It is understandable that many epidemiologists focus on other topics, such as infectious diseases, since infections are the number one cause of death according to WHO (11\% in 2016 in the neonatal period), while $5 \%$ of deaths in this period were caused by birth defects. While infections are the focal point of epidemiological studies there will remain little room for the experts to focus on other diseases, until deaths due to infections are contained. Although the infectious disease programs avail themselves of epidemiologists, other departments should benefit from this workforce equally.

The shortage of epidemiologists and public health human resources is on the rise and a real setback, because when it comes to successfully identifying and addressing national and international controversies is where the real struggle begins $[23,24]$.

\section{Discussion}

Prevention is key when it comes to lowering the mortality rate caused by CHD and other birth defects across the globe. The public health department is already involved in explaining to the population the risk factors that should be avoided throughout pregnancy and they are delivering a very high standard work. But is all of this information reaching the target audience? Are people truly understanding the risks that they impose on themselves and their children?

In our opinion, reaching out to the people in need and talking about maternal and fetal health at a level where every word is fully understood is the most delicate but powerful thing we can do for the population. Countries with low and middle income might not have access to prevention resources, might not understand the terminology and may be affected by the language barrier.

A great burden falls upon epidemiologists, because they are lacking in number and with so many topics being prioritized, and for a very good reason (i.e. infections), they tend to be understaffed and will not have the capacity to focus on studies regarding congenital heart defects. If there is no up to date information to bring upon the population and show them relevant data about how this problem is severely impacting our world, people will not focus on it at all because they will never understand the gravity of the issue and thus they will act with indifference. Also, based on complete data that can be delivered by epidemiologists, the public health workforce can guide the population of a country in the right direction. Of course online publicity, such as news, posters all across town is the right way to start, but nothing compares to a face-to-face education. People in poor countries may live far away from the city being pressured by expensive living conditions and may not have access to this kind of information. It is up to qualified personnel to deliver these messages eye to eye because people will respond better to it and there will be no room left for interpretation. Even though this type of participation takes time and financial resources, there is a lot at stake and society can lose so much more.

In pediatric surgery, especially in pediatric cardiac surgery, the physical and mental strain is seen more often than in any other medical fields, resulting in a lack of staff. Another problem in this area seems to be created through competition in the surgery department. In present times competition can't be made the main focus since collaboration is of utmost importance and in the majority of time is undoubtedly lacking. Medicine and scientific fields were not created to support and benefit only those around us, but everyone in need, regardless of their social and economical status.

While taking into consideration their physical wellness, we must not neglect mental health. Children who suffer from birth defects and their families should benefit from the help of specialized psychologists and psychiatrists who can help them overcome their fears and impediments and help them integrate into society.

Collaboration is crucial, especially in the healthcare domain, because everyone is affected by the health status of others. Low and middle income countries are in desperate need of help, which only the medical staff can provide.

\section{References}

1. Sunitha T, Prasoona KR, Kumari TM, et al. (2017) Risk factors for congenital anomalies in high risk pregnant women: A large study from South India. Egyptian Journal of Medical Human Genetics 18: $79-85$.

2. Aloui M, Nasri K, Ben Jemaa N, et al. (2017) Congenital anomalies in Tunisia: Frequency and risk factors. J Gynecol Obstet Hum Reprod 46: 651-655.

3. Lamichhane DK, Leem JH, Park M, et al. (2016) Increased prevalence of some birth defects in Korea, 2009-2010. BMC Pregnancy Childbirth 16: 61. 
4. Harris BS, Bishop KC, Kemeny HR, et al. (2017) Risk factors for birth defects. Obstet Gynecol Surv 72: 123-135.

5. Irvine B, Luo W, León JA (2015) Congenital anomalies in Canada 2013: A perinatal health surveillance report by the Public Health Agency of Canada's Canadian Perinatal Surveillance System. Health Promot Chronic Dis Prev Can 35: 21-22.

6. Moore JP, Aboulhosn JA (2017) Introduction to the Congenital Heart Defects: Anatomy of the Conduction System. Card Electrophysiol Clin 9: 167-175.

7. Togănel R (2016) Critical congenital heart diseases as lifethreatening conditions in the emergency room. Journal of Cardiovascular Emergencies 2: 7-10.

8. van der Linde D, Konings EE, Slanger MA, et al. (2011) Birth prevalence of congenital heart disease worldwide: A systematic review and meta-analysis. J Am Coll Cardiol 58: 2241-2247.

9. Bhardwaj R, Kandoria A, Marwah R, et al. (2016) Prevalence of congenital heart disease in rural population of Himachal - $A$ population-based study. Indian Heart J 68: 48-51.

10. Atwa ZT, Safar HH (2014) Outcome of congenital heart diseases in Egyptian children: Is there gender disparity? Egyptian Pediatriac Association Gazette 62: 35-40.

11. Yeh SJ, Chen HC, Lu CW, et al. (2013) Prevalence, mortality and the disease burden of pediatric congenital heart disease in Taiwan. Pediatr Neonatol 54: 113-118.

12. Patel N, Jawed S, Nigar N, et al. (2016) Frequency and pattern of congenital heart defects in a tertiary care cardiac hospital of Karachi. Pak J Med Sci 32: 79-84.

13. Torres-Cosme JL, Rolón-Porras C, Aguinaga-Ríos M, et al. (2016) Mortality from congenital heart disease in Mexico: A problem on the rise. PLoS One 11: e0150422.

14. Abqari S, Gupta A, Shahab T, et al. (2016) Profile and risk factors for congenital heart defects: A study in a tertiary care hospital. Ann Pediatr Cardiol 9: 216-221.

15. Pei L, Kang Y, Zhao Y, et al. (2017) Prevalence and risk factors of congenital heart defects among live births: A population-based cross-sectional survey in Shaanxi province, Northwestern China. BMC Pediatr 17: 18.

16. Helle EIT, Biegley P, Knowles JW, et al. (2018) First trimester plasma glucose values in women without diabetes are associated with risk for congenital heart disease in offspring. J Pediatr 195: 275-278.

17. Feng $Y$, Cai J, Tong $X$, et al. (2018) Non-inheritable risk factors during pregnancy for congenital heart defects in offspring: $A$ matched case-control study. Int J Cardiol 264: 45-52.

18. Shum KK, Gupta T, Canobbio MM, et al. (2018) Family planning and pregnancy management in adults with congenital heart disease. Prog Cardiovasc Dis 61: 336-346.

19. Foeller ME, Foeller TM, Druzin M (2018) Maternal congenital heart disease in pregnancy. Obstet Gynecol Clin North Am 45: 267-280.

20. Abouk R, Grosse SD, Ailes EC, et al. (2017) Association of US State implementation of newborn screening policies for critical congenital heart disease with early infant cardiac deaths. JAMA 318: 2111-2118.

21. Kumar RK (2015) Training pediatric heart surgeons for the future: A global challenge. Ann Pediatr Cardiol 8: 99-102.

22. Reichert HA, Rath TE (2017) Cardiac surgery in developing countries. J Extra Corpor Technol 49: 98-106.

23. Pearce N (2013) Global epidemiology: The importance of international comparisons and collaborations. OA Epidemiology 1: 15.

24. Rezaeian M (2016) Challenges of epidemiologists of developing countries in the 21st century. Acta Medica Iranica 54: 4-8.

DOI: $10.36959 / 856 / 487$

Copyright: (C) 2018 Cucu IA, et al. This is an open-access article distributed under the terms of the Creative Commons Attribution License, which permits unrestricted use, distribution, and reproduction in any medium, provided the original author and source are credited. 